\title{
EL RASTRO Y LA RUINA: TRAS LA HUELLA DE Antonio José Ponte y Abilio Estévez
}

\author{
Traces and Ruins: tracking Antonio José Ponte \\ AND ABILIO ESTÉVEZ
}

\section{Elena C. Palmero González}

Universidade Federal do Rio de Janeiro

Rio de Janeiro, RJ, Brasil

\section{Resumen}

Un tema recurrente en los estudios contemporáneos sobre la memoria es el de los rastros, huellas o vestigios memoriales. Tras una fecunda sistematización en el pensamiento filosófico, lo que podríamos llamar una teoría del rastro impacta hoy los estudios de la literatura y la cultura, sacando a la luz originales poéticas. Me intereso por la noción porque pretendo en este trabajo vincularla al tema de las autobiografías de artistas. Específicamente focalizo mi estudio en dos textos de carácter autobiográfico de escritores cubanos contemporáneos, que en la diversidad de sus estilos literarios, permiten al lector reconstituir un fragmento de la historia cultural reciente en la isla. Seguir las pistas dejadas por el autobiógrafo, escuchar el susurro de su relato íntimo, articulando su expresión subjetiva al horizonte problemático de lo colectivo son mis objetivos centrales al acometer el estudio de Inventario secreto de La Habana (2004) de Abilio Estévez y La fiesta vigilada (2007) de Antonio José Ponte.

\begin{abstract}
A recurring theme in contemporary studies on memory is that of the memory trace, footprint or vestige. Having already undergone ample systematisation in philosophical thinking, what we may call a trace theory is now greatly impacting literary and cultural studies, bringing to light very original poetics. This notion is of great interest to me, and in this study I intend to link it to the subject of artists' autobiographies. In specific, my study focuses on two autobiographical works by contemporary Cuban authors, both
\end{abstract}

\section{Resumo}

Um tópico frequente nos estudos contemporâneos sobre a memória é o dos rastros, marcas ou vestígios memoriais. Após uma fecunda sistematização no pensamento filosófico, o que poderíamos chamar de uma teoria do rastro impacta hoje os estudos da literatura e da cultura, trazendo à luz poéticas originais. Interesso-me por essa noção porque pretendo neste trabalho vinculá-la ao tema das autobiografias de artistas. Especificamente, meu artigo está focalizado em dois textos de caráter autobiográfico de escrito-
Palabras clave: Rastros; ruinas; discurso autobiográfico; literatura cubana contemporánea.

Keywords Traces; ruins; autobiographical discourse; contemporary Cuban Literature.

Palavras-chave: Rastros; ruínas; discurso autobiográfico; literatura cubana contemporânea. 
* (BERND, Zilá. Vestígios memoriais: fecundando as literaturas das Américas. In: Conexão Letras, n. 6, 2011: 9-15.)

* (PONTE, Antonio José. La fiesta vigilada. Barcelona: Anagrama, 2007.) of which, despite their differing literary styles, enable the readers to piece together a fragment of the island's recent cultural history. Following the traces left by the autobiographer, listening to the whisper of his intimate storytelling, inserting his subjective expression into the problematic perspective of a collective, are my main objectives in studying Inventario secreto de La Habana (2004) by Abilio Estévez and La fiesta vigilada (2007) by Antonio José Ponte. res cubanos contemporâneos que, na diversidade de seus estilos literários, permitem ao leitor reconstituir um fragmento da história cultural recente da ilha. Seguir as pistas deixadas pelo autobiógrafo, escutar o sussurro de seu relato íntimo, articulando sua expressão subjetiva ao horizonte problemático do coletivo, são meus objetivos centrais ao empreender o estudo de Inventario secreto de La Habana (2004), de Abilio Estévez, e La fiesta vigilada (2007), de Antonio José Ponte.

En los debates que animan el pensamiento contemporáneo sobre la memoria, un tema que viene siendo recurrente y que me interesaría colocar aquí como centro de reflexión es el de los rastros, huellas o vestigios memoriales. ${ }^{1}$ Tras una fecunda sistematización en el pensamiento filosófico de Walter Benjamin, Emanuel Levinas, Paul Ricoeur o Jacques Derrida, lo que podríamos llamar una teoría del rastro impacta hoy los estudios de la literatura y la cultura, sacando a la luz originales poéticas, de ahí que Zilá Bernd al enfocar los procesos de constitución de nuestras literaturas en las Américas nos convide a pensar en una estética dos vestigios, ${ }^{*}$ o que Antonio José Ponte cuando ensaya sobre la cultura contemporánea cubana, en su hermenéutica de la ruina, termine por articular una poética de la escritura.*

Me intereso por la noción porque pretendo en este trabajo vincularla al tema de las autobiografías de artistas. Específicamente focalizaré mi estudio en dos textos de carácter autobiográfico de escritores cubanos contemporáneos, que en la diversidad de sus estilos literarios e historias personales que cuentan, permiten al lector reconstituir un fragmento de nuestra historia cultural reciente. Ir tras las pistas que se solapan en el discurso confesional y memorial, escuchar los susurros que se esconden en gestos, imágenes, recuerdos menudos de la vida cotidiana, entrelazándose con los ruidos de la historia, puede asegurarnos una muy productiva lectura de un fragmento de la historia y la memoria cultural cuba-

\footnotetext{
${ }^{1}$ También frecuente en la bibliografía como trace (francés) o como spuren (alemán).
} 
nas. Si como asegura Leonor Arfuch, "la inmersión creciente en la propia subjetividad es sin duda un signo de la época, adquiere sin embargo otras connotaciones cuando esa expresión subjetiva se articula de modo elíptico o declarado, y hasta militante, al horizonte problemático de lo colectivo".* Leer esos textos, como testimonio individual, pero también colectivo, es acaso mi objetivo más hondo en este trabajo.

Como Arfuch, cuando selecciona el corpus a estudiar en su reciente libro, me intereso "por aquello activo y punzante, performativo, capaz de conformar y subvertir el relato, de aparecer sin ser llamado en una simple conversación, en una actualidad que convive con lo cotidiano aun sin emerger, sin mostrarse, formando parte de la historia común y de cada biografía".*

Sin intenciones totalizadoras de hacer un balance crítico de la noción de huella y sus múltiples traducciones (rastro, trazo, vestigio, residuo), retomo algunas referencias, que me parecen fundamentales para iniciar cualquier análisis. La primaria e imprescindible está en la obra de Walter Benjamin. Su reflexión sobre lo que podríamos llamar una teoría de la huella aparece diseminada en toda su obra, pero me detengo en el Libro de los Pasajes donde encuentro esta sugestiva afirmación: "la huella es aparición de una cercanía, por más lejos que pueda estar eso que la ha dejado atrás [...] En la huella nos apoderamos de la cosa".* Me interesa retener de ella dos detalles: el hecho de que la huella actualiza lo acontecido, ella no queda en el pasado, sino que es la aparición próxima de algo que se ha dejado atrás y el hecho de que a través de la huella, conocemos la cosa, o sea restauramos, de alguna manera, el objeto o el acontecimiento.

Otra referencia oportuna está en el pensamiento de Emanuel Levinas. En La huella del otro* el filósofo lituano afirma:

La huella no es un signo como otros, pero desempeña también el papel del signo. Puede ser tomada por un signo. El detective examina como signo todo aquello que marca, en el lugar del crimen, la obra voluntaria o involuntaria del criminal. El cazador sigue la huella de la caza mayor, que refleja la actividad y la dirección del animal que quiere alcanzar; el historiador descubre la civilización antigua como horizonte de nuestro mundo a partir sus vestigios. [La huella] tiene todavía esto de excepcional respecto de los otros signos: ella significa fuera de toda intención de hacer signo y fuera de todo proyecto en el cual ella sería el objetivo.*
* (ARFUCH, Leonor. Memoria y autobiografía: exploraciones en los límites. Buenos Aires: Fondo de Cultura Económica, 2013: 14.)

* (Idem.)

* (BENJAMIN, Walter. El libro de los pasajes. Madrid: Akal, 2005: 231.)

* (LEVINAS, Emanuel. La huella del otro. México: Taurus, 2001.)

* (Ibidem: 69.) 
* (GAGNEBIN, Jeanne Marie. O rastro e a cicatriz: metáforas da memória. In: Pro-Posições, vol. 13, N. 3 [39], 2002: 129.)

* (LEVINAS, Emanuel. La huella del otro. México: Taurus, 2001: 70.)

* (Ibidem: 70.)

* (RICOEUR, Paul. La memoria, la historia, el olvido. Buenos Aires: Fondo de Cultura Económica, 2004, 673 pp.)
O sea, que lo que distingue la huella del resto de los signos es, según Levinas, que ella significa fuera de toda intención de significar. El signo no logra apresarla, la huella escapa al significado. No es creada, es dejada. Quien trata de borrar huellas, deja otras, y son estas últimas las que nos interesan. Para decirlo con las palabras de Jeanne Marie Gagnebin, quien ha estudiado el tema con extraordinaria fecundidad: "Rigorosamente falando, rastros não são criados - como o são outros signos culturais e linguísticos, mas, sim, deixados ou esquecidos".*

Otra observación de Levinas es que la huella perturba el orden del mundo, toda vez que ella escapa a la presencia, pero deja el indicio:

La huella auténtica perturba el orden del mundo. Se da en sobre-impresión. Su significancia originaria se dibuja, por ejemplo, en las huellas que deja quien ha querido borrar las propias huellas para llevar acabo un crimen perfecto. Quien ha dejado huellas borrando las propias huellas no ha querido decir ni hacer nada con las huellas que deja. Ha perturbado el orden de manera irreparable.*

Y más adelante asegura:

El signo, además de lo que significa, es el pasaje de aquel que la ha dejado. La significancia de la huella duplica la significación del signo emitido en vista de la comunicación. El signo se mantiene en tal huella. En el caso de una carta, esta significancia residiría, por ejemplo, en la escritura y en el estilo de esta carta, en todo aquello que, en el momento mismo de la emisión del mensaje que captamos a partir del lenguaje de la carta y de su sinceridad, hace que alguien pase pura y simplemente. Esta huella puede de nuevo ser tomada por un signo.*

Este último pasaje de Levinas convoca a leer textos autobiográficos atentos al aliento que gravita en su enunciación, dejando que la voz autobiográfica pase, "pura y simplemente".

Una referencia insoslayable sobre el tema está en la obra de Paul Ricoeur. Recuperando la filosofía clásica, Ricoeur define la memoria a partir de una aporía insalvable: ser la presencia de una ausencia. Ricoeur se pregunta cuando reflexiona sobre la huella: "¿qué sucede con el enigma de una imagen, de una eikon - hablando en griego con Platón y Aristóteles -, que se muestra como presencia de una cosa ausente marcada con el sello de lo anterior?"* Ese enigma atraviesa los tres capítulos de su libro La memoria, la historia, el olvido, si bien es en el último capítulo, consagrado a una 
hermenéutica del olvido, donde Ricoeur reflexiona con extraordinaria riqueza sobre la ambivalente relación entre la huella y el olvido. Para Ricoeur, cuyo pensamiento relacional acude siempre a las aporías, el olvido puede significar la borradura de las huellas, pero también su distinción pues, como afirma el filósofo francés "hay olvido donde hubo huella".*

Y para completar esta red de referencias que intento tramar, acudo al pensamiento del escritor martiniqueño Patrick Chamoiseau sobre la trace-mémoire, una noción que podemos acompañar en Guyane, Traces-mémoires du bagne* y que traduzco al español como equivalente al concepto que discuto de huella o rastro memorial.

Chamoiseau explica la trace-mémoire como una presencia sin materia, un espacio olvidado por la Historia y por la Memoria. Obsérvese que la mayúscula se llena de sentido en el discurso de Chamoiseau. Historia, Memoria e Monumentos pertenecen al orden del poder (dominante, enraizado y vertical, son sus metáforas), en tanto se oponen a la memoria con minúscula y consecuentemente a la trace, esta caracterizada a partir de dualidades complementarias:

Je chante les mémoires contre la Mémoire. Je chante les Traces-mémoires contre le Monument [...] Qu'est-ce qu'une Trace-mémoires? C'est un espace oubliépar l'Histoire et par la Mémoire-une, car elle témoigne des histoires dominées, des mémoires écrasées et tend à les préserver [...] La Trace-mémoires n'est envisageable par un monument, ni par des stèles, ni par le document-culte de nos anciens historiens. La Trace-mémoires est à la fois collective et individuelle, verticale et horizontale, de communauté et trans-communautaire, immuable et mobile, et fragile. Alors que le monument témoigne toujours d'une force dominante enracinée et verticale. ${ }^{*}$

Concluyendo esta reflexión inicial, si la huella es la representación presente de una ausencia (Ricoeur); si en ella recuperamos el hecho y damos sentidos a sus espacios silenciados (Benjamin); si no es intencional, pero significa (Levinas); y si esa significación escapa al logos y a los grandes relatos legitimadores de la historia pero se expresa en la differance y puede ser recuperada a cualquier momento (Chamoiseau), una teoría de la huella así situada puede permitirnos leer textos autobiográficos procurando dar sentido a las huellas que quedaron impresas en su discurso.

Si el género autobiográfico instaura un espacio en el que los vestigios de un tiempo pasado se actualizan en la palabra testimo-
*(Ibidem: 13.)

* (CHAMOISEAU P., Hammadi R. Guyane, Traces-mémoires du bagne. Paris: Caisse nationale des monuments historiques et des sites, 1994,114 p.)

* (Ibidem: 16.) 
nial del sujeto que narra, podemos, a través del ejercicio hermenéutico, restablecer un dialogo con la historia, llenando sus intersticios, reinterpretando sus vacíos, recodificando el sentido de la huella.

Desde esa perspectiva leo Inventario secreto de La Habana (2004) de Abilio Estévez (Tusquets Editores, Barcelona, 2004) y La fiesta vigilada (2007) de Antonio José Ponte (Editorial Anagrama, Barcelona, 2007), dos textos de carácter híbrido donde se cruzan la crónica, las memorias, el ensayo y la autobiografía; dos proyectos narrativos que se articulan a partir de la productiva relación entre la memoria individual y una memoria cultural habanera e insular. También dos textos autorreferenciales producidos por intelectuales con vivencias históricas próximas: Abilio Estévez nace en 1954, tenía cinco años cuando triunfa la Revolución Cubana - hecho histórico que transforma sustancialmente la vida y la política cultural en la isla - y Antonio José Ponte nace en 1964, a cinco años del inicio de ese proceso de transformación, el más profundo y radical que vivió la sociedad cubana en su siglo XX. Digamos que sus trayectorias vitales siguen caminos compartidos, coincidiendo con el proceso cultural cubano de los últimos cincuenta años: vivieron la revolución triunfante del sesenta, las contradicciones del proceso en los setenta y la crisis del proyecto a partir de los ochenta. Apuntemos de paso que ambos emigraron del país hacia España comenzando el nuevo milenio - Abilio Estévez vive en Barcelona desde el 2000 y Ponte en Madrid desde 2007.

Pero no solo razones genéricas y biográficas motivan esta lectura compartida. También los leo como textos nacidos de la pérdida de un ideal utópico y del posicionamiento crítico de un sector intelectual cubano ante los rumbos históricos de la isla al finalizar el siglo veinte. Un posicionamiento sin gritos, sin estridencias y sobre todo, sin poses de disidencia, aun cuando disienten de todo. Son textos interpelativos, pero interpelan con contención. El tono íntimo, quedo y subjetivo, los caracteriza, de ahí el tipo de lectura que me propongo: ir tras las huellas de sus entredichos, de sus ironías, de las anécdotas más intrascendentes, del sujeto difuminado que los narra, de los personajes innominados que aparecen diseminados en sus páginas, de sus poéticas no declaradas. Para decirlo con Levinas, son esas huellas las que me interesan, porque son las que subvierten el orden del mundo. 
El Inventario secreto de La Habana se integra, en la obra de Abilio Estévez, a lo que podríamos llamar el ciclo narrativo de La Habana. Si observamos atentamente, la mayoría de sus novelas remiten obsesivamente a la isla y su capital en diferentes momentos históricos, convirtiéndose estas en tema y contexto privilegiado de su obra. Tuyo es el reino (1997), relata la entrada victoriosa de los rebeldes a la Habana de 1959, El navegante dormido (2008) tematiza los complejos años setenta, Los palacios distantes (2002) se sitúa en una Habana decadente y en ruinas, víspera del nuevo milenio y hasta El bailarín ruso de Montecarlo (2010), que parece situarse fuera de la isla, termina refiriéndola constantemente. En ellas, como la crítica ha observado, los tópicos de la memoria y el olvido son absolutamente transversales y en todas hay una reflexión en torno al paso del tiempo y el lugar de Cuba en la historia.

Inventario secreto de La Habana no es exactamente una novela, pero temáticamente vendría a completar ese ciclo narrativo habanero. Es un texto de género híbrido, que puedes ser leído de diversas maneras. En principio, fue pensado como una guía de viajes, según declara el escritor, una guía que, invirtiendo el mito turístico de La Habana, focalizase su lado oculto, su secreto íntimo, solo comprensible para iniciados en el rito de saber andar sus calles, saber mirar sus ruinas, reconocer en ese mundo palpitante y contradictorio de la urbe habanera los caminos de su singular identidad.

Pero también puede ser leído en la órbita del género memorial y autobiográfico. El libro cuenta la vida un sujeto relator, que el lector inmediatamente identifica con Abilio Estévez, su infancia, adolescencia y juventud en un barrio habanero, sus recuerdos de la vida cultural de la ciudad entre los años setenta y ochenta y el relato del presente en Mallorca y Barcelona. Pero no se piense en una autobiografía de artista del tipo convencional, a comenzar por la opacidad nominal de su sujeto emisor, que nunca declara explícitamente ser el escritor Abilio Estévez, aun cuando deje pistas absolutamente reconocibles para el lector.

También existe la opción de ver el libro como una crónica o diario de viaje, si pensamos que este se presenta como un cuaderno de apuntes que se escribe durante la estancia en diferentes ciudades europeas, solo que en ese caso no hay atención a cronologías, ni las ciudades visitadas son el objeto central de la descripción, ellas son más bien el eje potencializador de las memorias habaneras. 
En ese cruce de géneros, Estévez hace un inventario íntimo y subjetivo de La Habana, organizado en tres ejes narrativos: por una parte, un registro de lugares, personajes y recuerdos que articulan una ciudad secreta y personal; reflexiones del escritor que, textualizado en la figura de un yo narrativo testimonial, realiza un recorrido por las calles habaneras, sus monumentos, sus esquinas, sus parques, destacando lo anónimo y habitualmente silenciado de la ciudad. Ese inventario de bienes culturales se entrelaza con la autobiografía y el relato memorial, si consideramos los largos capítulos en que cuenta su vida y la relación personal que tuvo con escritores e intelectuales cubanos de los años setenta y ochenta, así como con una sui generis reflexión sobre la historia y la cultura cubana.

Por otra parte, una colección de versiones sobre la ciudad que, a modo de collage, son incluidas en la narración. Esos metatextos, de diferentes autorías (Alejandro de Humboldt, la Condesa de Merlín, Anaïs Nin, Federico García Lorca, Juan Ramón Jiménez, Alejo Carpentier, Virgilio Pinera, Graham Greene, Ernest Hemingway, entre otros), tienen a la Habana como centro y se encuentran ordenados cronológicamente. Tales recortes se presentan como una recopilación bibliográfica sobre la ciudad, un material cargado de tiempo y de memoria, que permite una mirada en diacronía al imaginario que se ha construido alrededor de La Habana y de la isla.

Finalmente, sobre estos dos ejes narrativos, se vislumbra un tercero que se corresponde con la propia escritura del texto. Así, en el presente de la escritura, cobran sentido el pasado, la memoria y la imaginación. Es esta instancia la que transforma el sentido originario de la palabra inventario, como "registro de bienes", por inventario, como "colección de invenciones", pues es allí que leemos una nueva y personal versión de la ciudad, La Habana imaginada de Abilio Estévez.

Importa resaltar que el relato subjetivo del pasado y los metatextos con reflexiones sobre La Habana no son lineales, ni consecutivos, tampoco guardan una rítmica alternancia, ni hay interés en paralelismos. La idea es presentar un registro polifónico de versiones de la ciudad, dentro de las cuales, la del sujeto enunciador es una más. Ya el nivel que textualiza la escritura se presenta como relato marco de todos esos relatos, funcionando como eje que potencializa la memoria y su registro escrito.

Estas tres instancias narrativas se organizan en seis capítulos y un epílogo. En el primero, el narrador desde un café en Palma 
de Mallorca comienza a rememorar La Habana. El mar, motivo detonante de su relato, origina una onda reflexión sobre la insularidad y la relación de las islas con el mar. Los tópicos del naufragio, el desarraigo y el miedo, asociados al mar y a la isla, comienzan su largo recorrido, entrelazándose con los recuerdos de una infancia feliz en el municipio habanero de Bauta. En los tres capítulos siguientes, desde Barcelona, se escriben los recuerdos de la adolescencia y la juventud. Toman aquí protagonismo el Malecón habanero y el barrio.

Formulándose como un repertorio de advertencias para descubrir una ciudad, el quinto es el capítulo donde el narrador deconstruye con mayor consistencia los mitos de La Habana, sobre todo el de su luz, su clima o su bulliciosa alegría, construyendo su mito personal de la ciudad, un mito que se elabora sobre la ruina de una Habana, otrora palaciega y elegante, hoy solar y hacinamiento. Es también en este capítulo donde reflexiona con mayor agudeza sobre el tema del olvido y la memoria: "Hay en La Habana personas obstinadas, a contracorriente, ajenas a la epidemia nacional de olvido y empeñadas en vivir una ciudad que no existe"* y coloca, jocosamente, el ejemplo de su padre, cuyos puntos de referencias de la ciudad siguen siendo edificios que hace años no existen, o que existen en ruinas, o del médico que refiere vivir "subiendo por la Agencia Ford, al lado del hipódromo"* cuando en Cuba ya no se venden carros Ford ni se apuesta caballos. Ambas son hermosas metáforas de como la memoria es presencia permanente de lo ausente.

Ese capítulo atesora las páginas más valiosas del libro en lo referido a la descripción del ambiente artístico y cultural de La Habana de los años cincuenta y sesenta. Los bares de la noche en la playa de Marianao, con sus músicos emblemáticos y las famosas orquestas de la época, los salones del Vedado o el ambiente íntimo y acogedor de la casa de José Lezama Lima, donde el maestro recibía a jóvenes escritores. A partir de este punto, lo autobiográfico toma un vuelo especial. El proceso formativo del artista que relata sus memorias habaneras comienza a correr paralelo al destino colectivo de una intelectualidad insular que se vio inmersa en el sustancial cambio político y cultural que sucedió a la Revolución de 1959. Conocemos el rumbo de la política cultural en el llamado decenio gris, dejando a la vista nombres, acciones, detalles que escaparían a cualquier historia cultural que se quiera hacer del periodo. Nos deja también una versión íntima y dolorosa del
* (ESTÉVEZ, Abilio. Inventario secreto de La Habana. Barcelona: Tusquets Editores, 2004: 196.)

*(Ibidem: 197.) 
hostigamiento vivido por Virgilio Piñera de parte de burócratas de turno con algún poder sobre los destinos culturales de la época, quedando el testimonio de su devoción por el maestro. Cuenta también de su amistad con María Luisa, viuda de Lezama Lima, hay anécdotas de Lezama, chismes del mundo cultural habanero de la época, a veces irónicos y maldosos, otras simpáticos y afectuosos. Contiene ese capítulo un momento de profunda reflexión sobre la oximórica relación que tuvieron Martí y Casal con la isla, y un recorrido histórico por la literatura cubana atenta a la relación de diversos escritores habaneros con su ciudad.

Ya el capítulo sexto vuelve a focalizarse en la escritura del libro que leemos, al que sigue un Epilogo, escrito en Stuttgart, con agradecimientos a las personas que facilitaron la escritura del libro, elemento paratextual que define poderosamente nuestra manera de leer el texto como relato autobiográfico.

Partiendo de esas coordenadas organizativas es posible ir al encuentro de historias mínimas, recuerdos íntimos, percepciones personales del autobiógrafo, seguir rastros que permitan articular una lectura alternativa del escenario histórico en que se insertan estas memorias. Hay una barrera, sin embargo, y es la opacidad del sujeto autobiográfico. Tras una prolija exposición de datos biográficos, el yo relator de estas memorias, se presenta siempre innominado, construyendo una imagen de doble mano: al tiempo que se explicita como sujeto memorioso, elude marcar una identidad nominal. Lo más próximo que sabemos de su identidad es que el padre se llamaba Abilio y hay también un reconocimiento de la autoría del texto teatral La verdadera culpa de Juan Clemente Zenea, o sea que las informaciones que conectan al autor de este inventario con el escritor Abilio Estévez son informaciones de naturaleza extratextual, que nosotros, como lectores, queremos leer como autobiográficas porque conocemos parte de esa historia cultural cubana que está siendo contada y parte de la vida del escritor y dramaturgo cubano Abilio Estévez.

Pensando en esa naturaleza ambigua del sujeto enunciador,

* (KANZEPOLSKY, Adriana. ¿Yo no soy el tema de mi libro? La fiesta vigilada de Antonio José Ponte. In: Abehache, São Paulo, v. 1, 2011. p. 59-69) me hago las mismas preguntas que se hace Adriana Kansepolsky cuando estudia La fiesta vigilada, de Antonio José Ponte:* ¿Qué tipo de yo se representa en un texto de pretensión autobiográfica cuando el discurso de la colectividad ha suplantado el discurso de la individualidad? ¿Qué tipo de relación entre lo público y lo privado establece un texto autobiográfico en una sociedad que embo- 
rrona los límites entre esos dos espacios? ¿Quien es, a fin de cuentas, ese yo que relata? Esas preguntas pairan en mi reflexión porque coincido en que las relaciones pragmáticas que establece este tipo de texto son expresivas de relaciones sociales muy singulares, tendientes a la polarización de los dos extremos de la enunciación: o la exteriorización de un yo colectivo (un sujeto que habla por voz de la comunidad), o la opción de un yo subjetivo e íntimo, pero que oculta "la persona", tan expuesta en las narrativas del yo contemporáneas. En este caso, se opta por el segundo modelo.

Conjeturo también que el sujeto, huidizo y expuesto, presente y ausente, múltiple y único de Estévez, sea el resultado natural de la invención memorial. Recordemos que en el acto de recordar, se construye una imagen de sí y que esa auto-invención, como explican Brunner y Weisser,* crea disyunciones entre el yo que relata en el instante del discurso y los yo esquematizados en la memoria. Ante la imposibilidad de hacer coincidir esos yos, Estévez opta por el juego de velar un nombre y exteriorizar funciones: el yo lector, el yo testigo, el yo flaneur, entre otras.

La opacidad nominal del sujeto relator puede leerse a su vez como la renuncia ostensible a ser el sujeto enunciador de un relato total y victorioso de la historia. Si nuestros autobiógrafos hispanoamericanos del siglo XIX asociaban, de manera casi biológica, sus vidas con el nacimiento de la nación, ${ }^{*}$ el relato autobiográfico de Abilio Estévez se adscribe a otra tradición, la del autobiógrafo que asocia su vida a la crisis de los proyectos utópicos del XX y en la que el sujeto enunciador no pretende ser la voz de la nación, ni de la Historia, solo una voz más en el concierto histórico.

Pensando en la llamada auto-confrontación textual, que Molloy define como ingrediente básico en la configuración del género autobiográfico en Hispanoamérica, no hay dudas de que el libro de Estévez se presenta como un cuaderno de apuntes personales que el narrador (leamos el escritor) lleva durante su periplo por varias ciudades españolas, mientras recuerda La Habana. También la escritura memorial se entrecruza con la propia reflexión sobre la memoria. Con extraordinaria agudeza, el narrador reflexiona sobre la naturaleza verbal y mítica de la memoria, apuntando para su lado incierto: "Nunca sabremos si todo tiempo pasado fue verdaderamente mejor, o así nos lo parece porque es tiempo leído, no vivido; tiempo descifrado por autores que lo han desmitificado y vuelto a
* (BRUNER, Jerome; WEISSER, Susan. La invención del yo: la autobiografía y sus formas. In: OLSOY, Daniel; TARANCE, Nancy (Org.). Cultura escrita y oralidad. Barcelona: Gedisa, 1995.)

* (MOLLOY, Silvia. Acto de presencia: La escritura autobiográfica en Hispanoamérica. México: Fondo de Cultura Económico, 1996.) 
* (ESTÉVEZ, Abilio, op. cit.: 73.)

* (Ibidem: 100.)

* (BUSTAMANTE, Fernanda. La narrativa de Abilio Estévez: hacia una estética de la sujeción-expolición. In: Aisthesis, Santiago de Chile, v. 47, 2010, p. 216-228.) mitificar para nosotros"; ${ }^{*}$ al tiempo que reconoce que una vida es en verdad el relato del evento guardado en la memoria:

Mi verdadera vida siempre ha ocurrido después. En el recuerdo. Como si los acontecimientos se sucedieran para ser re-observados (y relatados). Desde el tren, cuando ya no sirve otra cosa sino la memoria. Así veo deshacerse el presente, este presente, como si en él nada tuviera lugar, y sólo la memoria fuera capaz de demostrar que no ha sido así, y de recomponer los trozos de una sola dicha, y articular los rasgos de una persona o armar los atributos de una ciudad.*

Colateralmente a la problematicidad del sujeto relator, el otro tema que me interesaría tratar está referido al sistema verbal del texto. En el Inventario secreto de La Habana, la naturaleza creativa y proliferativa de la memoria hacen que la ciudad y el país sean representados como espacios sobresaturados de sentido. En correspondencia, los procedimientos retóricos que el escritor utiliza para representarlos se sustentan en la proliferación léxica, el excedente de sentido y en una suerte de agobio verbal, que Fernanda Bustamante ha caracterizado sagazmente como una "retórica de la saturación".*

Precisaría de una mayor reflexión para asegurar, aun cuando lo intuyo, que el sistema retórico de Estévez se sustenta en una suerte de inversión irónica del barroco insular, y digo irónica, porque si la concepción de la imagen y su relación con la palabra pueden ser la misma que encontramos en los maestros del barroco cubano, sus efectos de sentido son inversos, especialmente cuando se trata de describir la ciudad. Contrariamente a la retórica barroca de Lezama Lima o de Alejo Carpentier, por solo citar dos ejemplos emblemáticos, cuya expresión entusiasta de la ciudad se reconoce en una escritura de la acumulación, la proliferación verbal de Estévez alude al vaciamiento y la ausencia. Asistimos así a una proliferación de significantes huecos, a la ruina verbal, como si una Habana en ruinas, tuviese que ser relatada desde un discurso ruinoso.

Central en otros textos de Abilio Estévez (acaso Los palacios distantes sea el más emblemático), la ruina retorna al Inventario secreto de La Habana, no solo como referencia temática. Si las ruinas son fragmentos de tiempo y espacio que se resignifican en la construcción de una historia, en la obra de Abilio Esteves son también cuerpo verbal y materia prima para la constitución de una poética. 
El otro texto que me propongo atender, La fiesta vigilada de Antonio José Ponte, sigue las mismas coordenadas, ahora en un tono más elevado de impersonalidad, de ironía y con más conciencia en la conceptualización y estetización de la ruina.

Tras una rotunda obra ensayística registrada en libros como Las comidas profundas, Un seguidor de Montaigne mira La Habana, El libro perdido de los origenistas o El abrigo de aire, además del paso feliz por varios libros de poesía y de narrativa, Ponte nos entrega La fiesta vigilada (2007), un texto que armoniza ficción, ensayo y autobiografía y en el que recirculan temas y motivos caros al escritor: La Habana y sus ruinas, la memoria, el olvido. Como afirma Rafael Rojas: "La literatura de Ponte es una plataforma giratoria que proyecta la misma imagen desde todas las miradas posibles".*

La historia central que articula las partes del libro es la de un escritor que retorna a la isla después de un viaje al exterior. La isla es Cuba en los años noventa, de donde casi todos sus colegas se han ido, pero él insiste en vivirla. Su retorno, inexplicable para muchos, se fundamenta en la misma razón por la que Maupassant visitaba la Torre Eiffel. A pocas páginas de iniciar su relato, el narrador innominado, que es este escritor que retorna, nos cuenta como Maupassant, opositor acérrimo del proyecto de la Torre Eiffel, frecuentaba el engendro metálico asiduamente:

la torre Eiffel era el único punto de la ciudad desde donde no se divisaba la Torre. Y si la visitaba con tanta asiduidad era movido por el deseo de olvidar su existencia [...] Igual al Maupassant de esa anécdota, mi permanencia en Cuba estaba dictada por el deseo de olvidarla. Dentro de Cuba, no veía a Cuba.*

Ese sujeto relator, que significativamente no tiene nombre, conduce los cuatro bloques en que se estructura la obra y en los que ensayo y autobiografía confluyen de manera ingeniosa. El primero, "Nuestro hombre en La Habana (remix)", ofrece una lectura de la novela de Graham Green, corrosiva, irónica y llena de sentidos. Como el título anuncia, leemos la versión remixada de un mismo tópico, el espionaje en la Habana. En el segundo, "Caja negra de la fiesta”, toma protagonismo el tema del regreso de la fiesta a La Habana de los noventa. La intensa vida nocturna de la ciudad, reconocible en las novelas de Cabrera Infante y suspensa por tres décadas, volvía ahora a La Habana de los noventa, pero el eficaz sarcasmo de Ponte nos lo advierte: la fiesta vuelve, pero vigilada. El bloque siguiente, "Un paréntesis de ruina”, está dedicado

* (ROJAS, Rafael. Un arte de hacer ruinas, de Antonio José Ponte. In: Letras Libres, abril, 2006: 81.)

* (PONTE, Antonio José. La fiesta vigilada. Barcelona: Anagrama, 2007: 16-17.) 
* (BASILE, Teresa. Interiores de una isla en fuga. El "ensayo" en Antonio José Ponte. In: La vigilia cubana. Teresa Basile (org.). Rosario: Beatriz Viterbo Editora, 2009: 166.)

* (GONZALEZ Echevarría, Roberto. El puente de Ponte. In: Encuentro V. 44, 2007: 235.)
* (KANZEPOLSKY, Adriana. ¿Yo no soy el tema de mi libro? La fiesta vigilada de Antonio José Ponte. In: Abehache, v. $1,2^{\circ}$ semestre, São Paulo, 2011: 64.) a una reflexión sobre las ruinas de La Habana, ruinas vivas, ruinas en uso, de ahí que su pregunta central sea: ¿Como pensar una ruina habitada? Si la ruina testimonia la transformación del espacio de uso en espacio de la memoria, ¿cómo entender una ciudad que ya en el presente es memoria? Y el último bloque, "Una visita al Museo de la Inteligencia" cierra el libro volviendo al motivo del espía, del intruso, del fisgoneador de vidas ajenas, iniciado en el primer bloque.

Espionaje, fiesta y ruina son los pilares básicos del libro. Esos tres motivos, recorren el texto, articulándose de bloque a bloque de manera sutil, para tramar un tejido denso en términos conceptuales y narrativos. Lo ensayístico, dominante en el desarrollo de esos tópicos, no solapa el discurso del autobiógrafo. Como reconoce Teresa Basile, los reclamos de un intelectual como Ponte,

en choque con los preceptos ideológicos de la administración cultural cubana, solo pueden cobrar plena vida en el recinto íntimo del arte. La privatización de la escritura, el repliegue al interior del artista, su confinamiento al yo vienen a coincidir con el denominado "giro subjetivo", "literaturas del yo" o "giro autobiográfico" cuyo crecimiento en los últimos años advierten mucho críticos.*

No obstante, esta centralidad del individuo no significa una exposición de la intimidad del artista. Con agudeza González Echevarría distingue el tono impersonal y hasta reticente del sujeto enunciador del libro:

Hay poca autodefinición o revelación propia en La fiesta vigilada. [...] Sabemos poco sobre lo que siente Ponte, y menos sobre su vida sentimental, afectiva o erótica. Su postura es como la de un testigo culto, agudo, irónico de la vida cotidiana de la isla; pero un testigo vigilado, no sabemos si por fuerzas externas o internas.*

Adriana Kanzepolsky, por otra parte, piensa que el refugio en la intimidad opera como mecanismo de resistencia en la obra de Ponte y que, consecuentemente, el texto hurta la intimidad, pero no la niega:

Reconozco en La fiesta vigilada dos formas diversas de trabajar con la intimidad. En principio, lo íntimo se cuenta en otro espacio y en otra lengua, se cuenta contra el horizonte del portugués de Porto, donde pasa un año resguardado del encuentro con cubanos. Dentro de la Isla, lo íntimo se politiza y se traduce en un relato que hace de la memoria de la ciudad, pero sobre todo de su lectura del campo intelectual y de la tradición literaria cubanas, un asunto de familia.* 
Kanzepolsky se extiende en una bella y fundamentada argumentación, que no reproduzco por razones obvias de espacio, solo resalvo la manera en que la investigadora sigue rastros en la escritura, localiza frases, interpreta fragmentos, desmenuza eventos y los resignifica en su labor exegética. Finalmente, termina por convencerme: lo íntimo en Ponte es reticente (Echevarría), pero no exactamente ausente (Kanzepolsky).

Interrogado por Mónica Bernabé sobre la manera en que $\mathrm{La}$ fiesta vigilada está atravesada por lo autobiográfico, Antonio José Ponte responde:

La fiesta vigilada es mi texto autobiográfico más extenso, pero no el primero. Hay momentos declaradamente autobiográficos en varios de mis libros anteriores [...] y rachas de autobiografía en los poemas que he escrito. Aunque ninguno de esos libros ha tenido la ambición autobiográfica de La fiesta vigilada. Se trata, sin embargo, de una ambición sostenida de las riendas. Se trata de un impulso autobiográfico bastante contenido. Vigilado, si pensamos que la fiesta del título se refiere también al propio libro. Y de ahí el tono de sus páginas y la descripción del tono hecha por Roberto González Echevarría, con la que estoy de acuerdo en sus tres términos: quedo, irónico e impersonal.

Quedo por quieto, reposado, apacible hasta lo frío. Quería poner en ese libro la cólera que sentía (y que siento) al acercarme a ciertos temas. Y estaba seguro de que mi opción mejor pasaba por administrar esa cólera, por trabajarla en frío. Por recurrir a la ironía. No por casualidad esas páginas resultaron irónicas $[\ldots]$

$\mathrm{Y}$, del mismo modo en que sorteaba los peligros de un lenguaje público, tuve que sortear los peligros del recuento íntimo. No podía tratarse (lo sabía) de un retrato frontal, sino más bien de uno velado. Contar lo autobiográfico pasaba entonces por el cultivo de lo impersonal. La tarea consistía en narrar en tanto persona del modo menos personal posible. Lo cual, en el fondo, remite a la cuestión de cuán verosímil se siente uno mientras escribe. $\mathrm{O}$, apartando la escritura, cuán verosímil se es.*

En esa apuesta a la impersonalidad, los personajes de La fiesta vigilada tampoco llevan nombre. La sátira a burócratas, comisarios, escritores frustrados devenidos funcionarios incluye negarles un nombre, lo que de alguna manera es condenarlos al olvido. No obstante, un lector avisado, coterráneo y próximo generacionalmente de Ponte, sabe colocar nombres donde él pone vacíos.

Pero su reticencia es generalizada. Una posición más afectuosa con otros personajes no pasa de nombrarlos por una inicial mayúscula: "M. vestía con elegancia”; “Tendrías que viajar, me advirtió
* (BERNABÉ, Mónica. Un puente, un gran puente: ciber-entrevista a Antonio José Ponte. In: La vigilia cubana. Teresa Basile (org.). Rosario: Beatriz Viterbo Editora, 2009: 251.)

*(PONTE, Antonio José, op. cit.: 12.) 
* (Ibidem: 14.)

* (Ibidem: 214.)

* (Ibidem: 47.)

* (MORAN, Francisco, Un asiento y Ponte entre las ruinas. In: La vigilia cubana. Teresa Basile (org.). Rosario: Beatriz Viterbo Editora, 2009: 48.)
B.”;* “Aquí está mi expediente, bufó G.”** El universo familiar es referido por "la abuela", "el hermano mayor", "la casa paterna" y los conocidos por "el fotógrafo", "el teatrista" o "el maestro de salsa". Ganan un sintagma los "viejos escritores cubanos", a los cuales el protagonista está estudiando - guiño autorreferencial muy ingenioso, si recordamos que Ponte tiene un ensayo sobre los Origenistas. En el caso de Virgilio Pińera lo refiere como "el viejo escritor" o "uno de los viejos escritores cubanos de quienes me ocupaba".* No hay referencias a mitos nacionales - si bien sabemos que Ponte es un serio estudioso de José Martí - ni a grandes figuras literarias del pasado más inmediato. González Echeverría aprecia esa distancia y la considera un gesto honesto y humilde en medio de la moda de las citaciones y de las influencias lezamianas que pesa sobre la generación de Ponte. Curiosamente con músicos y cineastas, así como con hechos vinculados a estas artes, Ponte no escatima en nombres y detalles.

La narración de hechos relevantes y efemérides históricas también es acometida fríamente por Ponte, que con toda intención huye de las vallas, los carteles y las denuncias en las plazas públicas. De igual manera, el sujeto enunciador del texto se muestra reticente a asumir cualquier rol de representatividad y, como en el texto Abilio Estévez, renuncia a ser la voz colectiva o centralizadora de cualquier relato legitimador de una Historia total y única.

Ya en la recta final del análisis quiero detenerme en el tópico de la ruina, que considero el núcleo articulador de la escritura de Ponte. Núcleo que no se limita al tratamiento temático, ni a la representación de la imagen física y simbólica del escombro y la decadencia arquitectónica de La Habana, sino que involucra también una mirada de las cosas, de las personas, de los destinos históricos, deviniendo también una poética, una manera de asumir la escritura misma.

Con extraordinaria originalidad, Francisco Morán observa:

Ponte no contempla o medita simplemente frente al espectáculo de la ruina, sino que la reproduce, añade ruina a la ruina. Él es la Scherezada que multiplica la ruina a través de un relato que está siempre comenzando [...] Construye, escribe: es lo mismo. La escritura de Ponte no avanza, tuguriza.*

Esta reflexión me parece útil para comprender el movimiento interno de la obra. Avanzamos de un bloque a otro y ciertos motivos vuelven, amplificando la significación, pero con los mismos mate- 
riales. Ese reciclaje crea una sensación en el lector de vasos comunicantes, como si atravesase en el texto túneles, andamios, espacios divididos y subdivididos como los edificios en ruinas de La Habana. Si lo ruinoso en Abilio Estévez es reconocible en el cuerpo verbal del texto; en Ponte, es más un ejercicio autorreflexivo, una manera de componer sus textos, un sistema poético y, sobre todo, una forma de pensar, de ahí que él mismo se autodenomine ruinólogo.

Solemos pensar la ruina como memoria y como testimonio, pero la ruina es también posibilidad arqueológica, en ese sentido es también exploración, es una manera de indagar el mundo. El verdadero ruinólogo se apodera de la ruina para devolver la historia a la escritura, se apropia de los fragmentos para construir una nueva historia. El progreso humano, como nos enseña Benjamin, no está en la suma de conquistas, sino en la acumulación de ruinas. Ponte parece decirnos que ciertas ruinas y ciertos derrumbes son necesarios para contar con una nueva historia.

En estos textos autobiográficos, que he leído al sesgo, procurando en sus huellas, la reconstrucción de un fragmento de historia reciente - como otros, si consideramos la eclosión que el género viene teniendo en la literatura cubana contemporánea - se reconstituye un discurso historiográfico, sin dudas más vital y auténtico que cualquier compendio de historia. Escritos desde la intimidad autobiográfica, ellos apelan a una memoria colectiva y son testimonio vivo de una época. Ellos perturban el orden, ellos prometen otro tiempo.

Elena C. Palmero González é professora Titular de Literaturas Hispano-americanas na Universidade Federal do Rio de Janeiro (UFRJ). Atua no Programa de Pós-graduação em Letras Neolatinas dessa instituição. Tem Doutorado em Ciências Filológicas pela Universidad Central de Las Villas (Cuba, 1997) e Pós- Doutorado em Literatura Latino-americana pela Université Paris IV-Sorbonne (França, 2007). Coordenadora do GT/ ANPOLL Relaçôes Literárias Interamericanas. Bolsista de Produtividade em Pesquisa do CNPq. Autora de Relatar el tiempo: Alejo Carpentier (2003), No reino de Alejo Carpentier: doze ensaios críticos (2009); co-organizadora da antologia de contos cubanos Dizer o marl Decir el mar (2008) e autora de diversos ensaios sobre literatura cubana e latino-americana contemporâneas contidos em livros e revistas acadêmicas do Brasil, Canadá, Cuba, Espanha, França, México e Venezuela. E-mail: <elenap@vetorial.net>. 